\title{
ДОСЛІДЖЕННЯ ДИСПЕРСНОГО СКЛАДУ ПИЛУ ПРИ ВИРОБНИЦТВІ ТЕПЛОІЗОЛЯЦИИНИХ МАТЕРІАЛІВ
}

\author{
Гаджиєв Едуард Назімович, аспірант \\ Україна, Харків, «Український Науково-Дослідний Інститут Екологічних Проблем»,
}

DOI: https://doi.org/ 10.31435/rsglobal_ws/28022019/6348

\author{
ARTICLE INFO \\ Received: 26 December 2018 \\ Accepted: 21 February 2019 \\ Published: 28 February 2019

\section{KEYWORDS} \\ cleaning efficiency, \\ dust-cleaning equipment, \\ fine dust, \\ thermal insulation materials, \\ mineral wool, \\ dispersed dust composition.
}

\begin{abstract}
The problem of air pollution with environmentally hazardous dust with a particle size of up to 10 microns at plants for the production of thermal insulation materials is considered. The purpose of this work is to study the dispersed composition of dust in the production of insulation materials (such as mineral wool), and to determine the effectiveness of the existing gas cleaning equipment, which traps pollutants. The dispersed composition of the dust generated at the plant for the production of thermal insulation materials, and the dispersed composition of the dust collected by the dust-cleaning equipment was investigated. Experimentally and with the use of computer programs, it has been established that the efficiency of extracting fine dust from dustcleaning equipment does not exceed $78 \%$. It is established that the dust of mineral wool entering the aspiration system is dominated by particles with a size from 2.5 microns to 25 microns. Dust with a $\mathrm{SiO} 2$ content of up to $70 \%$, which is released during unloading and transportation of raw materials (dolomite, basalt), enters the atmospheric air without purification. At the same time, particles with a size of up to 60 microns and up to 72 microns dominate in atmospheric air, respectively. The main characteristics of the dust necessary for the objective selection of dust-cleaning equipment are determined.
\end{abstract}

Citation: Гаджиєв Е. Н. (2019) Doslidzhennia Dyspersnoho Skladu Pylu pry Vyrobnytstvi Teploizoliatsiinykh Materialiv. World Science. 2(42), Vol.1. doi: 10.31435/rsglobal_ws/28022019/6348

Copyright: (C) 2019 Гаджиєв Е. Н. This is an open-access article distributed under the terms of the Creative Commons Attribution License (CC BY). The use, distribution or reproduction in other forums is permitted, provided the original author(s) or licensor are credited and that the original publication in this journal is cited, in accordance with accepted academic practice. No use, distribution or reproduction is permitted which does not comply with these terms.

Введення. Пил (суспендовані тверді частинки) $є$ одним 3 найпоширеніших забруднювачів атмосферного повітря в Україні. Його викиди займають третє місце після викидів діоксиду сірки та оксиду вуглецю, причому 3 тенденцією до підвищення [1]. Найнебезпечнішим для людини та навколишнього природного середовища є дрібнодисперсний пил [2], а саме $\mathrm{TЧ}_{10}$ - суспендовані тверді частинки з розміром від 2,5 мкм до 10 мкм, та $\mathrm{TЧ}_{2,5-}$ суспендовані тверді частинки 3 розміром частинок менше 2,5 мкм (ТЧ 10 та $\mathrm{TЧ}_{2,5}$ - за позначенням Держстат України). В Україні ще не встановлено нормативи допустимої концентрації $\mathrm{TЧ}_{2,5}$ і ТЧ Імплементація Директиви 2008/50/ЄС Європейського Парламенту та Ради про якість атмосферного повітря та чистіше повітря для Європи передбачає розроблення нормативноправових актів, що встановлюють нормативи допустимої концентрації суспендованих твердих частинок $\left(\mathrm{TЧ}_{2,5}\right.$ та $\left.\mathrm{TЧ}_{10}\right)$ в атмосферному повітрі та забезпечення їх моніторингу. Нормування концентрації ТЧ $Ч_{10}$ та ТЧ 2,5 в повітрі в різних країнах світу приведені в табл.1. 
Результати дослідження. В загальному промисловому виробництві України наразі за темпами розвитку лідируючі позиції займають підприємства будівельної індустрії а в їх складі підприємства по виробництву теплоізоляційних матеріалів, які $€$ значними джерелами неорганічного пилу [4]. Рівень екологічної небезпеки цих підприємств посилює особливість їх розташування: у містах, зазвичай близько до житлової забудови. Забруднюючі речовини цих підприємств $є$ опосередкованим викидом пилу з вмістом $\mathrm{SiO}_{2}$ до $70 \%$, фенолформальдегіду, а отже, джерелом негативного впливу на здоров'я населення. До того ж неорганічний пил підприємств які виробляють мінеральну вату - потенційний алерген, здатний викликати гострі та хронічні алергічні реакції [5].

Таблиця 1. Допустимі ТЧ 2,5 та ТЧ 10 в атмосферному повітрі

\begin{tabular}{|c|c|c|}
\hline \multirow{2}{*}{ Країни та організації } & \multicolumn{2}{|c|}{$\begin{array}{l}\text { Середньорічна концентрація }\left(\mathrm{C}_{\text {c.p. }}\right) \\
\text { частинок, мкг } / \mathrm{M}^{3}\end{array}$} \\
\hline & $\mathrm{T} \mathrm{Y}_{10}$ & ТЧ 2,5 \\
\hline $\mathrm{EC}$ & $28-20$ & $17-12$ \\
\hline BOO3 & 20 & 10 \\
\hline США & - & 12 \\
\hline Австралія & - & 8 \\
\hline Японія & - & 15 \\
\hline
\end{tabular}

При обгрунтуванні вибору пилоочисного обладнання для ефективного захисту атмосферного повітря від забруднення пилом (особливо дрібнодисперсним) головним критерієм $€$ його інгредієнтний та дисперсний склад. [11].

Відомо, що в технологічних процесах виробництва мінеральної вати у якості сировина використовуються: базальт, доломіт, кокс, які у складі викидних газів можуть потрапляти в атмосферне повітря. Проте інформація про технологічні властивості та дисперсний склад пилу кондитерських підприємств в науково-технічній літературі вкрай обмежена. Так, за [12] в пилу цукру та крохмалю переважають ( $\geq 80 \%$ ) частинки розміром до 10 мкм (табл. 2), а серед них найбільший вміст мають частинки 1 мкм.

Таблиця 2. Дисперсний склад пилу підприємств з виробництва мінеральної вати [12]

\begin{tabular}{|l|l|l|l|l|}
\hline \multirow{2}{*}{ Вид пилу } & \multicolumn{4}{l|}{ Відсоток вмісту частинок пилу розміром, мкм } \\
\cline { 2 - 5 } & до 1 мкм & $1-5$ мкм & $5-10$ мкм & $10-20$ мкм \\
\hline Доломіт, базальт & 21,8 & 67,3 & 39,3 & 18,7 \\
\hline Мінеральна вата & 36,3 & 46,4 & 33,2 & 13,0 \\
\hline
\end{tabular}

Пил, що утворюється на транспортерної лінії та при вивантаженні сировини для утворювання мінеральної вати, в основному має розмір частинок $2-45$ мкм, середній розмір частинок $\mathrm{d}_{50}$ (медіанний діаметр, при якому кількість частинок крупніших $\mathrm{d}_{50}$ дорівнює кількості частинок дрібніших $\mathrm{d}_{50}$ ) складає 24 мкм [13]. Пил мінеральної вати складається 3 частинок до 72 мкм, а середній розмір частинок $\mathrm{d}_{50}$ складає 36 мкм[14].

Для очистки викидних газів від забруднюючих речовин на підприємствах з виробництва теплоізоляційних матеріалів (мінеральної вати) використовуються циклони, які мають ефективність уловлювання 80 - $85 \%$ (частинок більше 10 мкм), а також рукавні фільтри з ефективністю 95 - 96 $\%$ (частинок більше 1 мкм) [15]. Чи забезпечує така ефективність пилоочисного обладнання достатній рівень екологічної безпеки підприємства неможливо визначити без відомостей про дисперсний склад пилу, що надходить до газоочисного обладнання [16].

Дослідження екологічно важливих характеристик пилу проводили за [17]. Визначення дисперсного складу пилу виконували методом мікроскопії - вимірюванням частинок із застосуванням окуляр мікрометра, та при обробці фотографій пилу у Corel Draw Graphics Suite 2018, розрахунок характеристик частинок пилу виконували у ImageJ. Теоретичні розрахунки та обробку експериментальних даних виконували із застосуванням комп'ютерних програм Microsoft Excel ta DisAdp. 
Експериментально досліджували пил, що утворюється на підприємстві 3 виробництва теплоізоляційних матеріалів, яке виробляє мінеральну вату. При виготовленні цієї продукції утворюється пил неорганічний з вмістом $\mathrm{SiO}_{2}$ до $70 \%$ та смоли фенолформальдегіду.

У даній роботі досліджували:

- пил мінеральної вати, відібраний з витяжного повітроводу поперечної та повздовжньої різки мінеральної вати до циклону, та пил мінеральної вати, відібраний з бункеру циклону;

- пил мінеральної вати, відібраний 3 витяжного повітроводу камери волокноутворення;

- пил доломіту, базальту, коксу, з місця вивантаження та завантаження сировини (пилоочисне обладнання відсутнє).

Результати дослідження дисперсного складу пилу підприємства 3 виробництва мінеральної вати наведено в табл. 3. Яквидно, в пилу мінеральної вати, доломіту, базальту та коксу, який утворюється на підприємстві з виробництва мінеральної вати, переважають ТЧ 10 та $\mathrm{TЧ}_{2,5}$, а це свідчить про те, що пил $є$ дрібнодисперсним.

Результати дослідження дисперсного складу зразків пилу мінеральної вати, відібраних 3 витяжного повітроводу до циклону, показують, що в ньому переважають ТЧ 2,5 . Сумарний процентний вміст частинок з розміром до 10 мкм, тобто ТЧ 2,5 та ТЧ $\mathrm{TЧ}_{10}$, складає 95,9\%.

За результатами дослідження дисперсного складу пилу мінеральної вати, який надходить до циклону з камери волокноутворення, визначено, що у його складі переважають $\mathrm{TЧ}_{10}$. Сумарний процентний вміст $\mathrm{TЧ}_{2,5}$ та ТЧ 10 у пилу мін. вати становить $83,4 \%$.

Таблиця 3. Дисперсний склад пилу підприємства з виробництва мінеральної вати

\begin{tabular}{|l|l|l|l|l|l|}
\hline \multirow{3}{*}{ Вид пилу } & $\begin{array}{l}\text { Ділянка відбору } \\
\text { пилу }\end{array}$ & \multicolumn{3}{|l|}{ Вміст частинок кожної фракції, \% } \\
\cline { 2 - 6 } & $\begin{array}{l}\text { Менше 2,5 ммвід 2,5 мкм до } \\
\left(\mathrm{TЧ}_{2,5}\right)\end{array}$ & $\begin{array}{l}\text { Біл мкм (ТЧ } \\
10\end{array}$ & $\begin{array}{l}\text { Медіанний } 10 \text { мкм } \\
\text { розмір часток, мкм }\end{array}$ \\
\hline \multirow{2}{*}{ Мін. Вата } & До циклону & $62,5 \pm 11,7$ & $33,4 \pm 13,2$ & $3,8 \pm 4,5$ & $2,03 \pm 0,81$ \\
\cline { 2 - 6 } & Уловлений & $42,7 \pm 10,3$ & $54,1 \pm 5,2$ & $8,3 \pm 4,0$ & $3,44 \pm 0,82$ \\
\hline
\end{tabular}

Аналіз результатів дослідження дисперсного складу пилу доломіту, базальту, коксу, який викидається в атмосферне повітря без очистки, показав, що у його складі практично однакова кількість $\mathrm{TЧ}_{2,5}$ та ТЧ

За допомогою комп'ютерної програми DisAdp, розробленої на мові C\#, виконано обробку експериментальних даних та розраховано медіанний діаметр частинок пилу $\mathrm{d}_{50}$. Результати розрахунків за цією програмою звірено з розрахунками в програмі Microsoft Excel. Для пилу мінеральної вати, який подається у циклон, $\mathrm{d}_{50}$ склав $1,96 \pm 0,74$ мкм. Це свідчить про те, що у пилу мінеральної вати до циклону переважають $\mathrm{TЧ}_{2,5}$ (найбільш небезпечні для людини та навколишнього середовища). Для пилу мінеральної вати, уловленого циклоном, $\mathrm{d}_{50}$ склав $3,48 \pm$ 0,89 мкм, що говорить про переважний вміст ТЧ 10 у даному пилу. Різниця між медіанними розмірами пилу до циклону та пилу, уловленого циклоном, свідчить про те, що ТЧ 2,5 мінеральної вати малоефективно уловлюються очисним обладнанням і потрапляе в атмосферне повітря.

Отже, в атмосферне повітря міста викидається без очистки пил, 50 \% якого згідно [18] за своєю дисперсністю здатне проникати аж в легені дихальної системи людини.

Для підбору пилоочисного обладнання необхідно встановити наступні характеристики пилу: діаметр частинок, що визначає межу, нижче якої знаходиться $10 \%, 25$ \%, $75 \%$ та $90 \%$ частинок пилу відповідно $\mathrm{d}_{10}, \mathrm{~d}_{25}, \mathrm{~d}_{75}, \mathrm{~d}_{90}$, коефіцієнт відносного діапазону розподілу частинок $\Delta_{\text {тч }}$ (розподіл кількості частинок за діаметрами: чим менше $\Delta_{\text {Tч}}$, тим менша розбіжність у кількості частинок кожного діаметра, чим більше число, тим більша розбіжність у кількості частинок кожного діаметра).

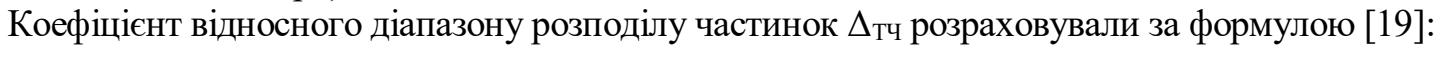

$$
\Delta_{\mathrm{T \Psi}}=\left(\mathrm{d}_{90}-\mathrm{d}_{10}\right) / \mathrm{d}_{50}
$$

Для визначення цих характеристик побудовано інтегральні криві розподілу частинок пилу (рис. 1-3). 3 рис. 1 видно, що для пилу мінеральної вати з витяжного повітроводу перед циклоном $\mathrm{d}_{10}$ становить 0,3 мкм, $\mathrm{d}_{25}-0,7$ мкм, $\mathrm{d}_{75}-3,6$ мкм, а $\mathrm{d}_{90}-7,3$ мкм, $\Delta_{\text {тч }}-4,7$. Для пилу мінеральної вати, затриманого циклоном, $\mathrm{d}_{10}$ становить 0,4 мкм, $\mathrm{d}_{25}-1,1$ мкм, $\mathrm{d}_{75}-6,2$ мкм, а $\mathrm{d}_{90}-9,2$ мкм, $\Delta_{\text {Тч }}-3,3$. 


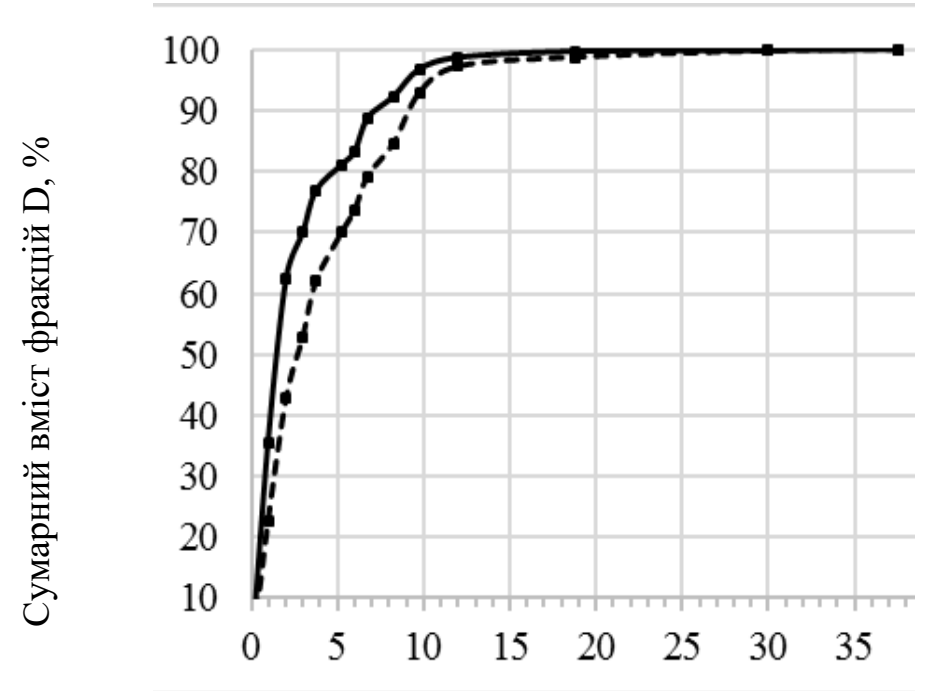

Діаметр частинок $\mathrm{d}$, мкм

Рис. 1. Інтегральна крива розподілу частинок пилу мін. вати

(-—-пил до ичиклону, ---п-- пил затриманий циклоном)

Характеристики для пилу мін вати з камери волокноутворення визначено за рис. 2. Для пилу мін. вати 3 витяжного повітроводу перед циклоном $\mathrm{d}_{10}$ становить 1,9 мкм, $\mathrm{d}_{25}-3,4$ мкм, $\mathrm{d}_{75}$ $-9,5$ мкм, a d90 $-17,6$ мкм, $\Delta_{\text {Tч }}-2,8$. Для пилу мін. вати, затриманого циклоном, $\mathrm{d}_{10}$ становить 4 мкм, $\mathrm{d}_{25}-6,7$ мкм, $\mathrm{d}_{75}-12,1$ мкм, a $\mathrm{d}_{90}-15$ мкм, $\Delta_{\mathrm{Tч}}-1,2$.

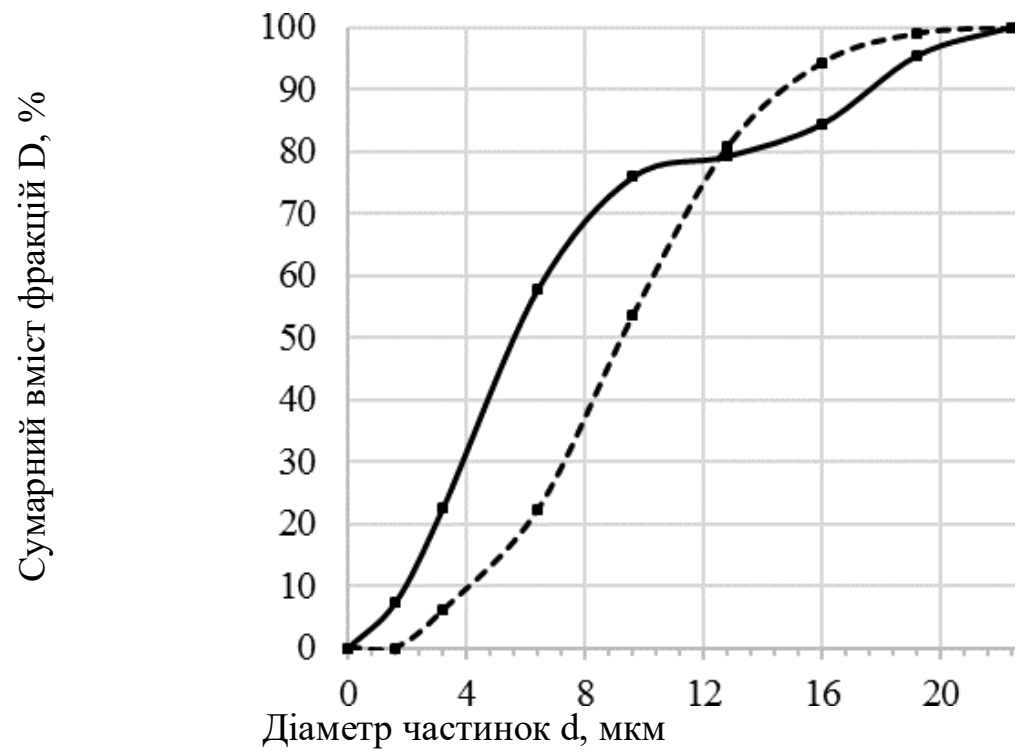

Рис. 2. Інтегральна крива розподілу частинок пилу мін. вати

(-ш- пил до цииклону,

--- пил з цииклону)

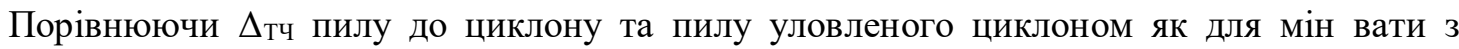
дільниці різки та камери волокноутоврення, можна сказати, що пил уловлений циклоном має більш рівномірне розподілення кількості частинок за діаметрами, у той час як у пилу до циклону розподілення кількості частинок за діаметрами нерівномірне, з перевагою у сторону найбільш дрібних частинок пилу (для мін. вати 3 дільниці різки $3,3<4,7$, для мін. вати 3 камери волокноутворення $1,2<2,8)$. 
Характеристики для пилу доломіту, базальту, коксу, який викидається в атмосферне повітря без очистки, визначено за рис. 3 . Діаметр $\mathrm{d}_{10}$ становить 2,2 мкм, $\mathrm{d}_{25}-5,7$ мкм, $\mathrm{d}_{75}-15,2$

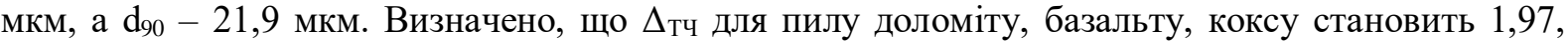
отже розподілення кількості частинок за діаметрами досить рівномірне.

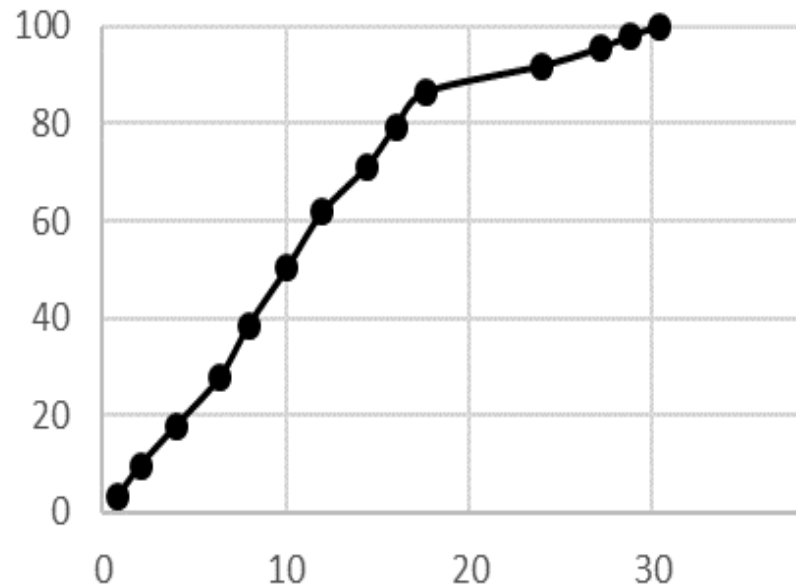

Діаметр частинок $\mathrm{d}$, мкм

Рис. 3. Інтегральна крива розподілу частинок пилу доломіту, базальту, коксу

Відомо, що кут нахилу інтегральної кривої до осі абсцис $є$ показником ступеню дрібнодисперсності пилу (чим більший кут, тим більш дрібнодисперсним є пил) [20]. Отже, за зменшенням ступеня дрібнодисперсності дослідженого пилу сипучі речовини, які утворюють цей пил, можна розташувати в наступний ряд: мін. вату з дільниці різки - мін. вату з камери волокноутворення - доломіт, базальт, кокс. Причому, пил мін. вати має дуже високий ступінь дрібнодисперсності пилу як в зразках до циклону, так і в зразках пилу уловленого циклоном.

Визначено моди $-\mathrm{d}_{\text {mod }}$ (діаметр частинок, що мають найбільший відсоток від загальної кількості), максимальний $\left(\mathrm{d}_{\max }\right)$ та мінімальний $\left(\mathrm{d}_{\min }\right)$ діаметри, діапазон найбільш вірогідних діаметрів частинок дослідженого пилу $\mathrm{d}_{\mathrm{pr}}$ (табл. 4).

Таблиця 4. Характеристики пилу підприємства з виробництва мінеральної вати

\begin{tabular}{|l|c|c|}
\hline Ділянка відбору пилу & $\mathrm{d}_{\bmod }$, & $\mathrm{d}_{\min }$, \\
\hline До циклону & 0,97 & 0,3 \\
\hline Уловлений & 0,97 & 0,4 \\
\hline До циклону & 6,4 & 1,6 \\
\hline Уловлений & 9,6 & 3,2 \\
\hline До циклону & $\mathrm{d}_{\max }$, & $\mathrm{d}_{\mathrm{pr}}$, \\
\hline Уловлений & 37,5 & $0,97-2$ \\
\hline До циклону & 37,5 & $0,97-4$ \\
\hline Уловлений & 22,4 & $2-6,4$ \\
\hline
\end{tabular}

Як видно, для пилу мінеральної вати як до циклону, так і для уловленого циклоном, $\mathrm{d}_{\mathrm{mod}}$, $\mathrm{d}_{\max }$ однаковi, $\mathrm{d}_{\min }$ практично однакові, але $\mathrm{d}_{\mathrm{pr}}$ відрізняються, що свідчить про необхідність проведення додаткових заходів саме з уловлення частинок пилу мінеральної вати з розміром до 2 мкм. $d_{\max }$ як для пилу мінеральної вати від камери волокноутоврення до циклону, так $\mathrm{i}$ для уловленого циклоном однаковий. Різниця у $\mathrm{d}_{\bmod }, \mathrm{d}_{\min }$ та $\mathrm{d}_{\mathrm{pr}}$ для пилу мінеральної вати від камери волокноутворення до циклону та для уловленого циклоном свідчить про необхідність проведення додаткових заходів 3 уловлення найдрібніших частинок пилу з розміром до 6,4 мкм. Отже при виборі пилоочисного обладнання необхідно враховувати переважаючий вміст частинок до 2,1 мкм. Для пилу доломіту, базальту, коксу $\mathrm{d}_{\text {mod }}$ дещо зміщений до правої межі $\mathrm{d}_{\mathrm{pr}}$, 
проте $\mathrm{d}_{\min }$ такий же як для пилу мінеральної вати , a $\mathrm{d}_{\max }$ вдвічі менше ніж в ньому. Тому для підбору пилоочисного обладнання необхідно враховувати більш широкий діапазон уловлюваних частинок доломіту, базальту, коксу, а саме до 16 мкм (що не зовсім привабливо для використання фільтрів).

Висновки: 1. За даними експериментальних досліджень пил усіх речовин, що використовуються у виробництві мінеральної вати (неорганічний $\mathrm{SiO}_{2}$ до $70 \%$, мінеральної вати)відноситься до дрібнодисперсного, тобто пилу з розміром частинок менше 10 мкм, який $\epsilon$ екологічно найнебезпечнішим.

2. У пилу мінеральної вати на дільниці різки, що надходить до циклону переважають частинки 3 розміром до 2 мкм, пил мінеральної вати, уловлений циклоном, складається переважно 3 частинок розміром до 4 мкм. В пилу мінеральної вати від камери волокноутворення, що надходить до циклону, переважають частинки 3 розміром від 2 до 6,4 мкм, а в пилу, уловленому циклоном - від 6 до 12 мкм.

3. Орієнтовно пилоочисне обладнання на підприємстві пропускає не менше $20 \%$ найбільш не- безпечного дрібнодисперсного пилу ТЧ ${ }_{2,5}$ таТЧ $_{10}$.

\section{ЛІТЕРАТУРА}

1. Викиди забруднюючих речовин та парникових газів у атмосферне повітря від стаціонарних джерел забруднення на підприємствах будіндустрії, 2017. - 34 с.

2. Particulate Matter (PM) Pollution [Electronic re- source] / United States Environmental Protection Agency. 2017 - Access mode: https://www.epa.gov/pm-pollution/health-and- environmental-effects-particulatematter-pm (last ac-cess: 20.10.2017) - Title from thescreen.

3. Азаров В.Н. Комплексная оценка пылевой обстановки и разработка мер по снижению запыленности воздушной среды промышленных предприятий: Ростов-на-Дону, 2014. - 47 с.

4. Архипов А.Н. Экологичность комплексной переработки минерального сырья для производства строительных материалов. Горн. Информ.-аналит. Бюл. Моск. Грного ун-та, 2011, №1, с. 119-120.

5. Бочарова К. А. Неотложные состояния в аллергологии: клиника, диагностика, профилактика анафилактических и анафилактоидных реакций / К. А. Бочарова - Белгород: ООО «Константа», 2010. - 60с.

6. Directive 2008/50/EC of the European Parliament and of the Council of 21 May 2008 on ambient air quality and cleaner air for Europe [Electronic resource] / European Parliament and the Council. - 2017.

7. Ambient air pollution: a global assessment of exposure and burden of disease / WHO Library Cataloguingin-Publication Data. - Switzeland, Geneva: WHO Document Production Services, 2016. - 121 p.

8. EPA-452/R-12-005 Regulatory Impact Analysis for the Final Revisions to the National Ambient Air Quality Standards for Particulate Matter / U.S. Environmental Protection Agency Office of Air Quality Planning and Standards Health and Environmental Impacts Division Research Triangle Park, 2012. - 474 p.

9. National standards for criteria air pollutants 1 in Australia [Electronic resource] / Department of the Environment and Heritage. - 2005. - Access mode: http://www.environment.gov.au/aboutus/accountability-reporting/expenditure (last access: 30.10 .2017 ) - Title from thescreen.

10. Outline of Report on PM Particle Substance (PM 2.5) Review Board / Tokyo Metropolitan Office. - 2011 - - 4p.

11. Беляева Л.И. Сборник удельных показателей выбросов загрязняющих веществ в атмосферу от предприятий стройиндустрии/ К. И. Беляева и др. - Курск: Росгипросахагропром, 1990. - 80с.

12. Алиев Г.М.-А. Техника пылеулавливания и очистка промышленных газов. М.: Металлургия, 2007. - 544.

13. Stobnicka A. Exposure to flour dust in the oc- cupational environment / A. Stobnicka, Rafai L. Gyrny // International Journal of Occupational Safety and Ergonomics. - 2015. - № 21 (3). - P. 241 -249.

14. Абрамов И.Н. Опыт внедрения и эксплуатации установок абсорбционой очистки газовых выбросов минераловатного производства // Теплопроект, Москва, 2005, с. 35-43.

15. Kn0p A. andScheib W., ChemistryandApplicationof Phenolic Resin.s', Springer-Verlag, BerlinHeidelberg, NewYork, $2009-4-5 p p$.

16. Гурець Л.Л. Вибір високоефективного га- зоочисного обладнання з метою запобігання забруднення атмосфери / Л.Л. Гурець // Екологічна безпека: наук. журн. - Кременчук : КрНУ, 2009. - № 2. - С. 69 -72.

17. Коузов П. А. Основы анализа дисперсного состава промышленных пылей и измельченных материалов / П. А. Коузов. - Л.: Химия, 2007. - 264 с.

18. Thoracic and respirable particle definitions for human health risk assessment [Electronic resource]/J. Brown, T. Gordon, O. Price, B. Asgharian // Particle and Fibre Toxicology. - 2013. - Access mode: http://www.particleandfibretoxicology.com/content/10/ 1/12 (last access: 20.10.2017) - Title from thescreen.

19. Horiba scientific: guidebook to particle size analysis. - Irvine: Horiba Instruments, INC, 2017. - $34 \mathrm{p}$.

20. Кошкарев С.А. Дисперсионный анализ пыли выбросов в системах аспирации производства цемента с использованием усовершенствованной экспериментальной установки [Электронный ресурс]/ С.А.Кошкарев, Л.Я. Соломахина, А.Редван // Инженерный вестник Дона: Электронный науч. журн. - 2014. - № 3 